\title{
Radioactive Cleaning Robot
}

\author{
Emily Stachowicz
}

AD Robotics Initiative - CCI

5 August 2020

This manuscript has been authored by Fermi Research Alliance, LLC under Contract No. DE-AC02-07CH11359 with the U.S. Department of Energy, Office of Science, Office of High Energy Physics. 


\section{Radioactive Cleaning Robot}

\section{Problem}

- Particle Accelerator Gives off Radioactive Dust

- Dust build up can be harmful

- Dust requires yearly, expensive cleaning

- Area must be shut down during this

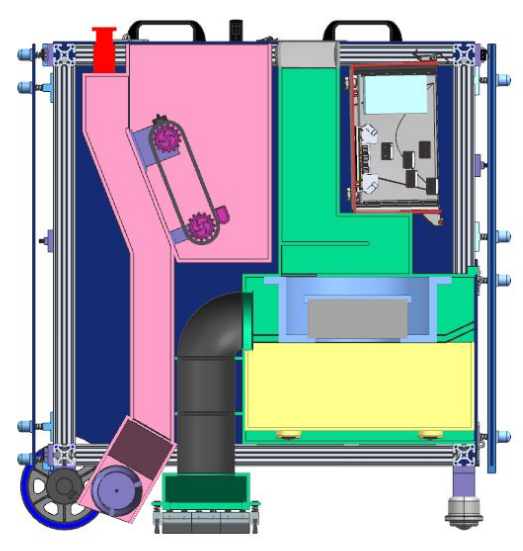

\section{Solution}

- Radioactive Cleaning Robot can be used attract and contain the harmful dust

- Can be ran year round to ensure constant cleaning 


\section{Radioactive Cleaning Robot}

\section{Functionality}

- Distributes “Tough Guy” powder

- Special powder attracts radioactive dust

- Sucks up powder and dust combination

- Air flows through the vacuum into the reservoir

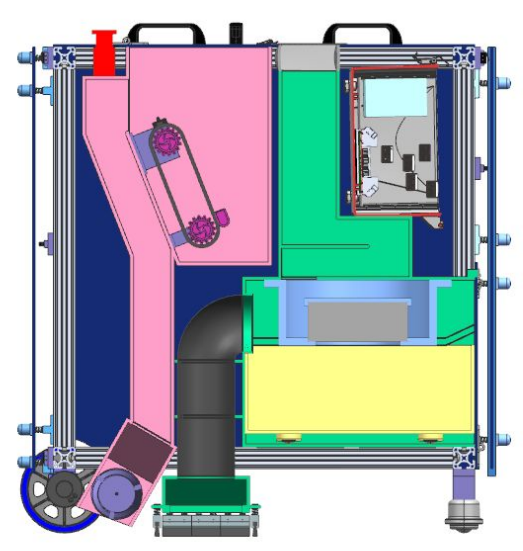

- Dust falls downward while air passes through the vacuum fan and filter

- Remaining dust settles in the baffle system

- Dust reservoir is removed and emptied via hatch/ramp combination

- Powder is refilled through top hatch 


\section{Concept Sketches}



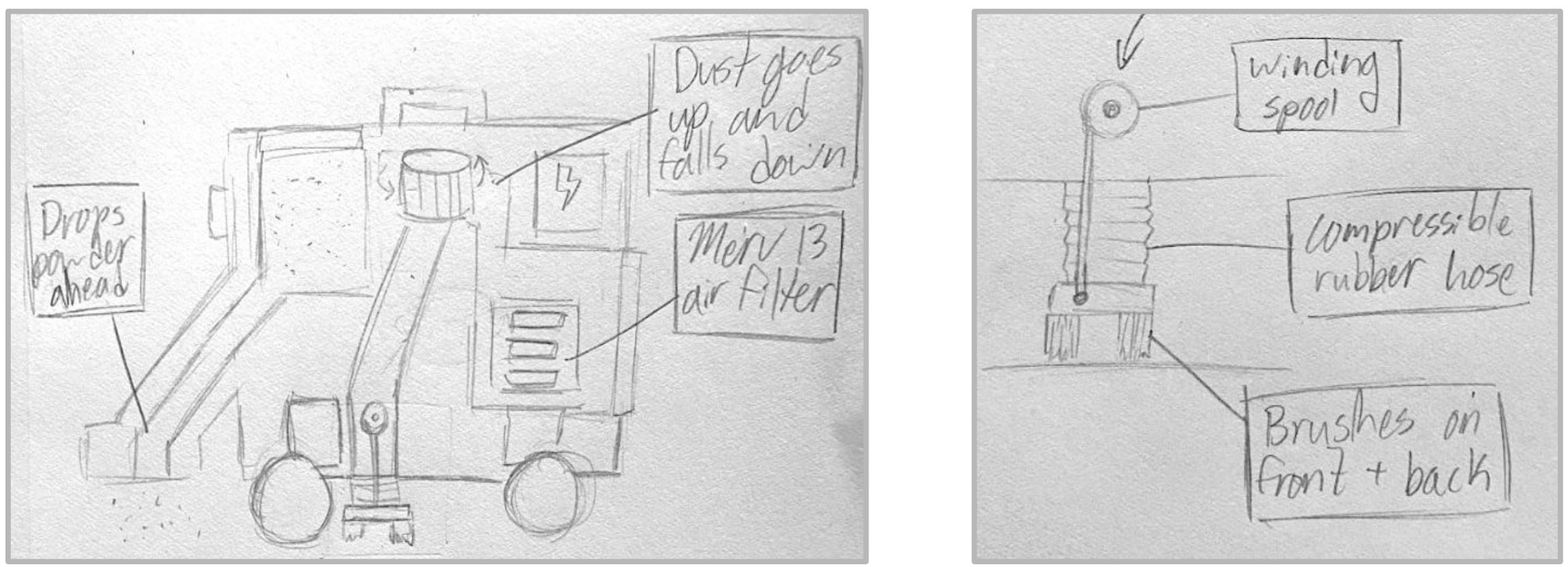

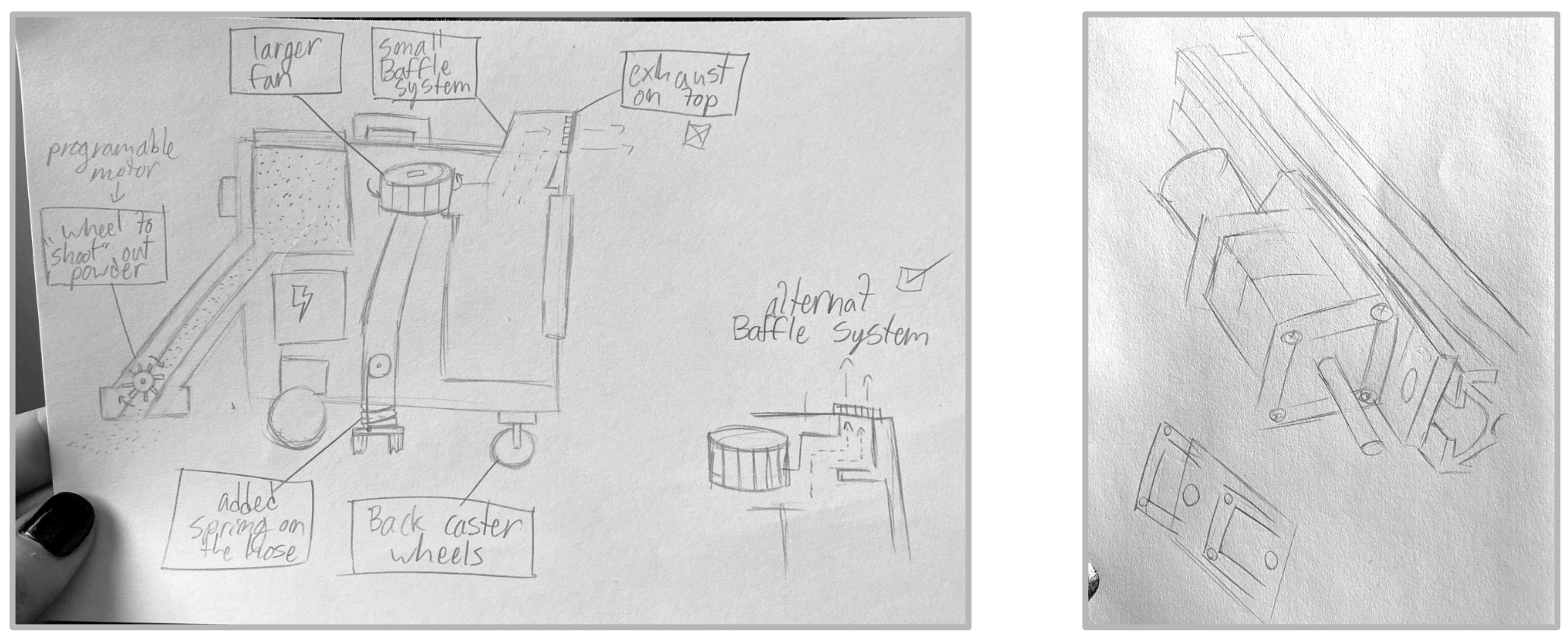


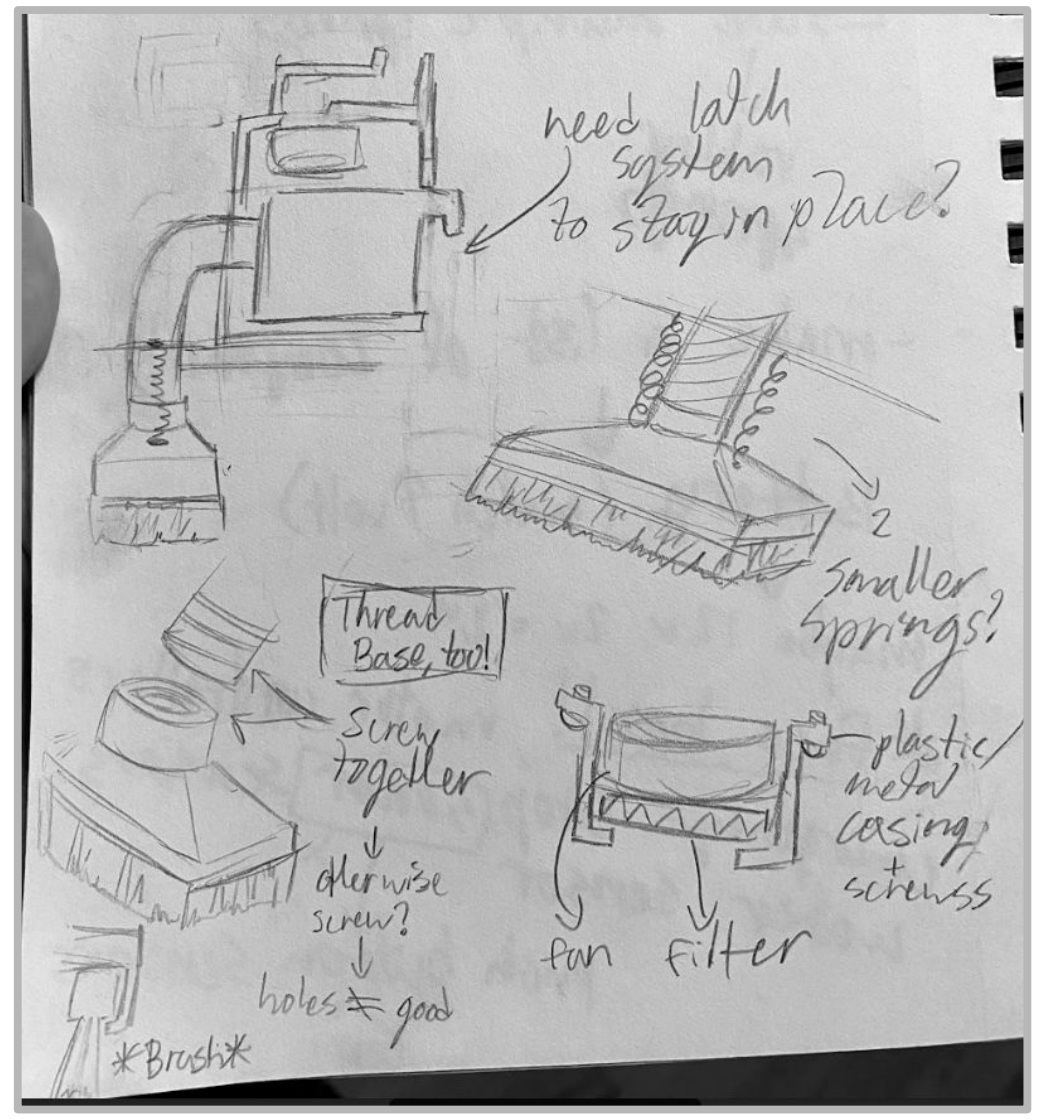



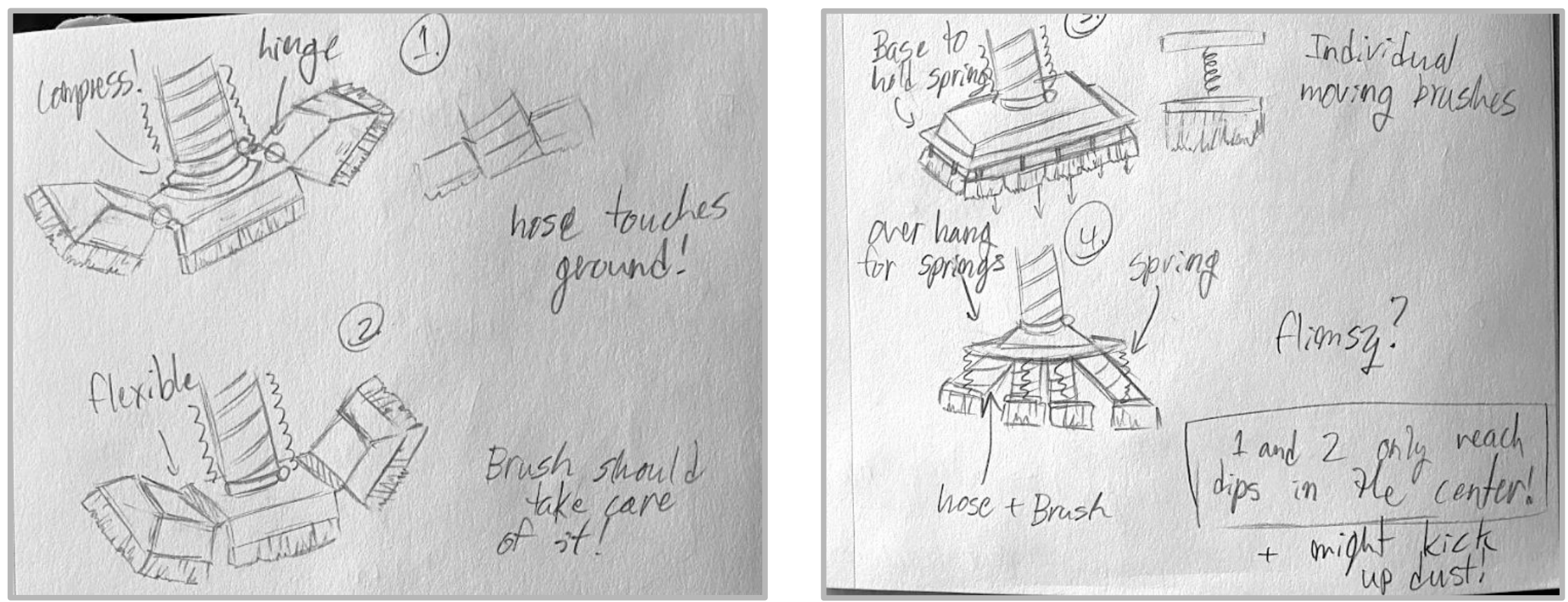

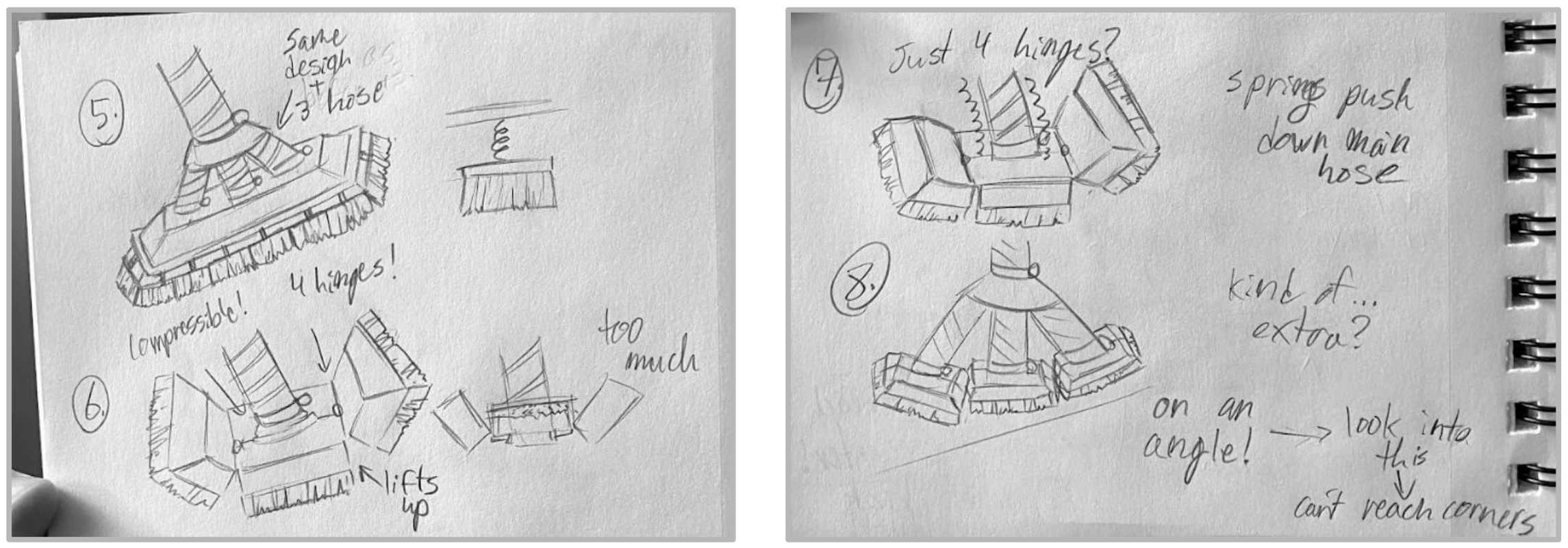


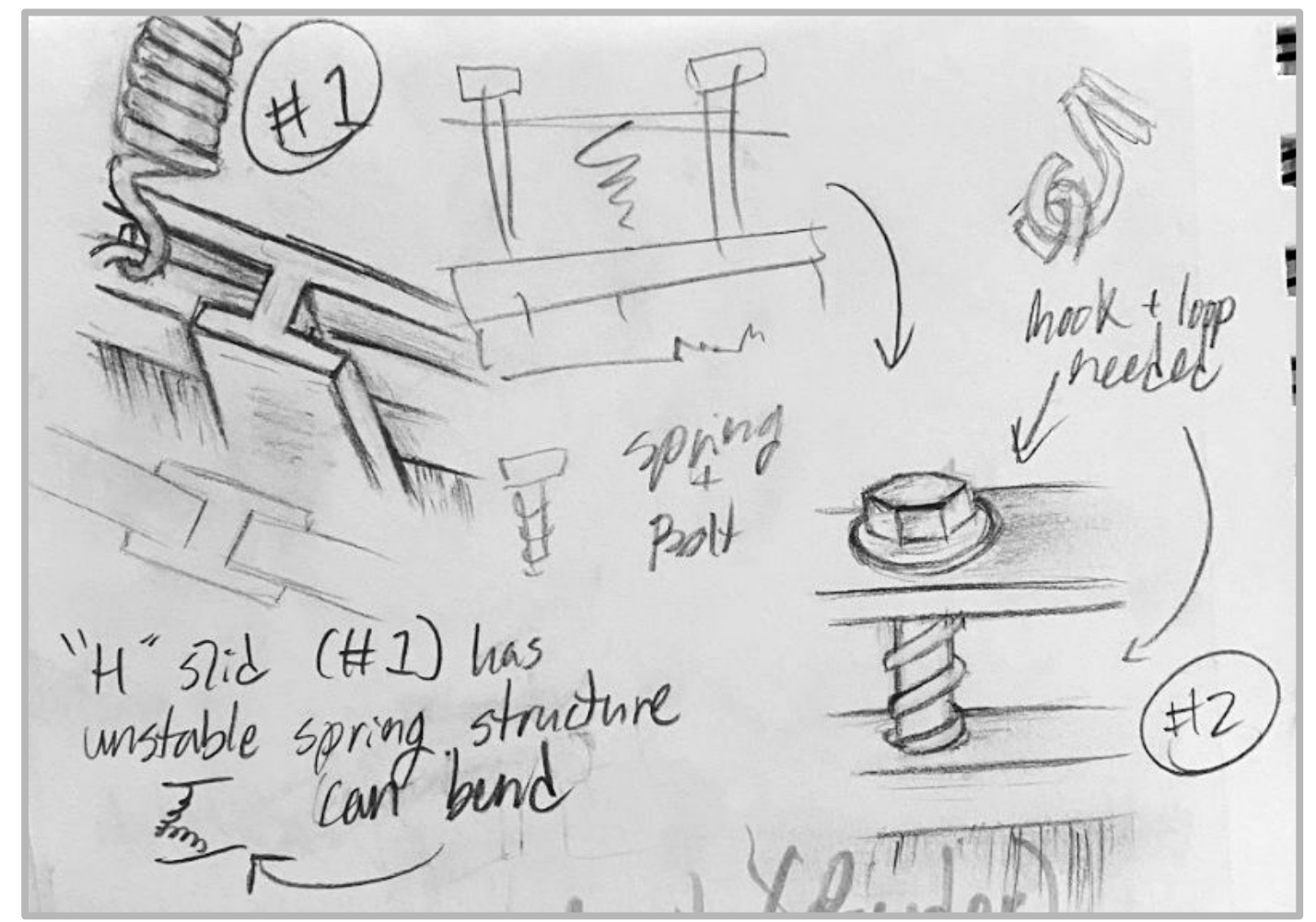




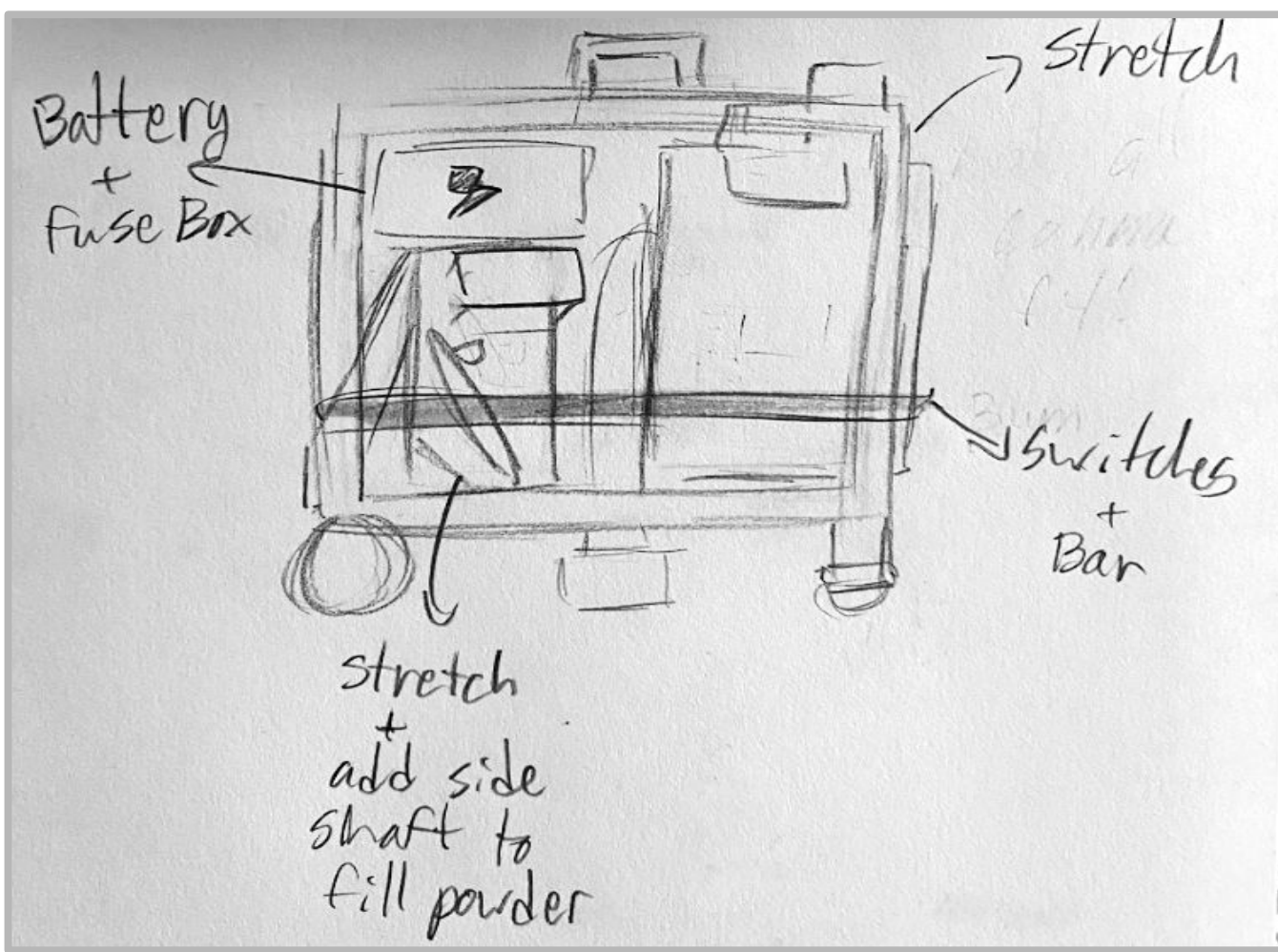

军 Fermilab 

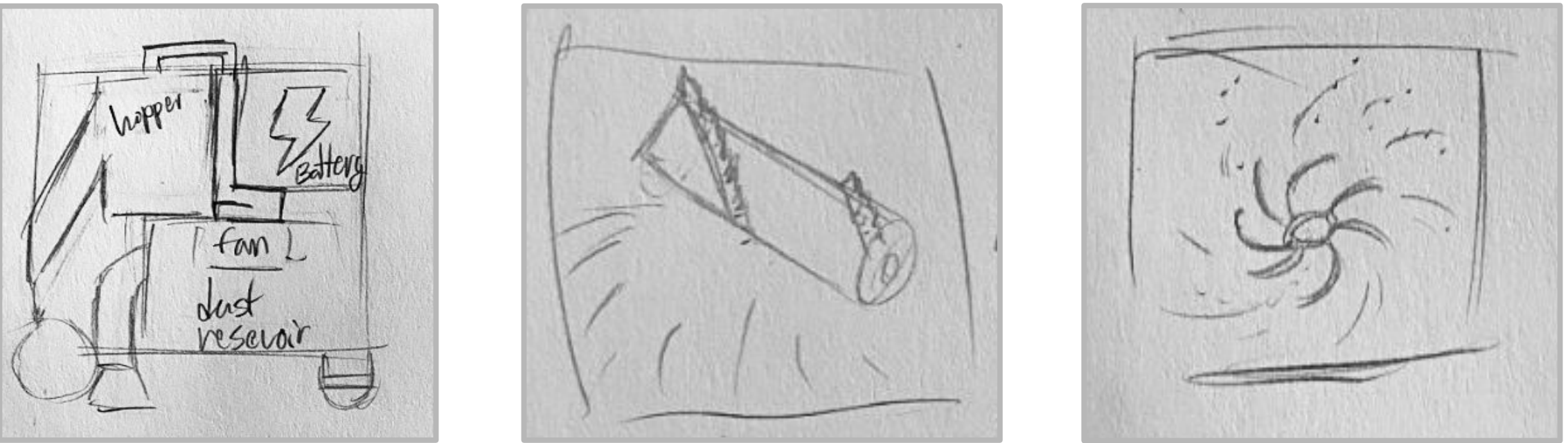


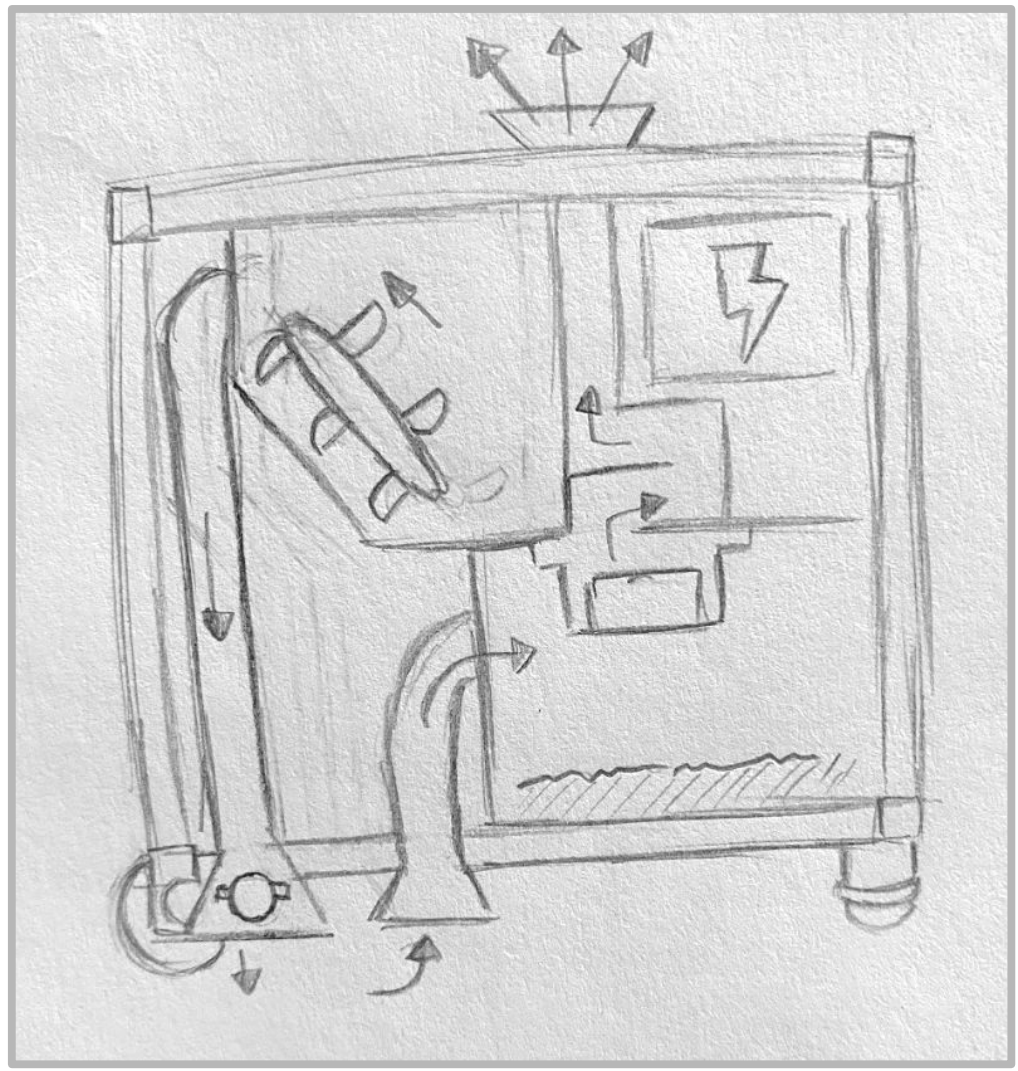



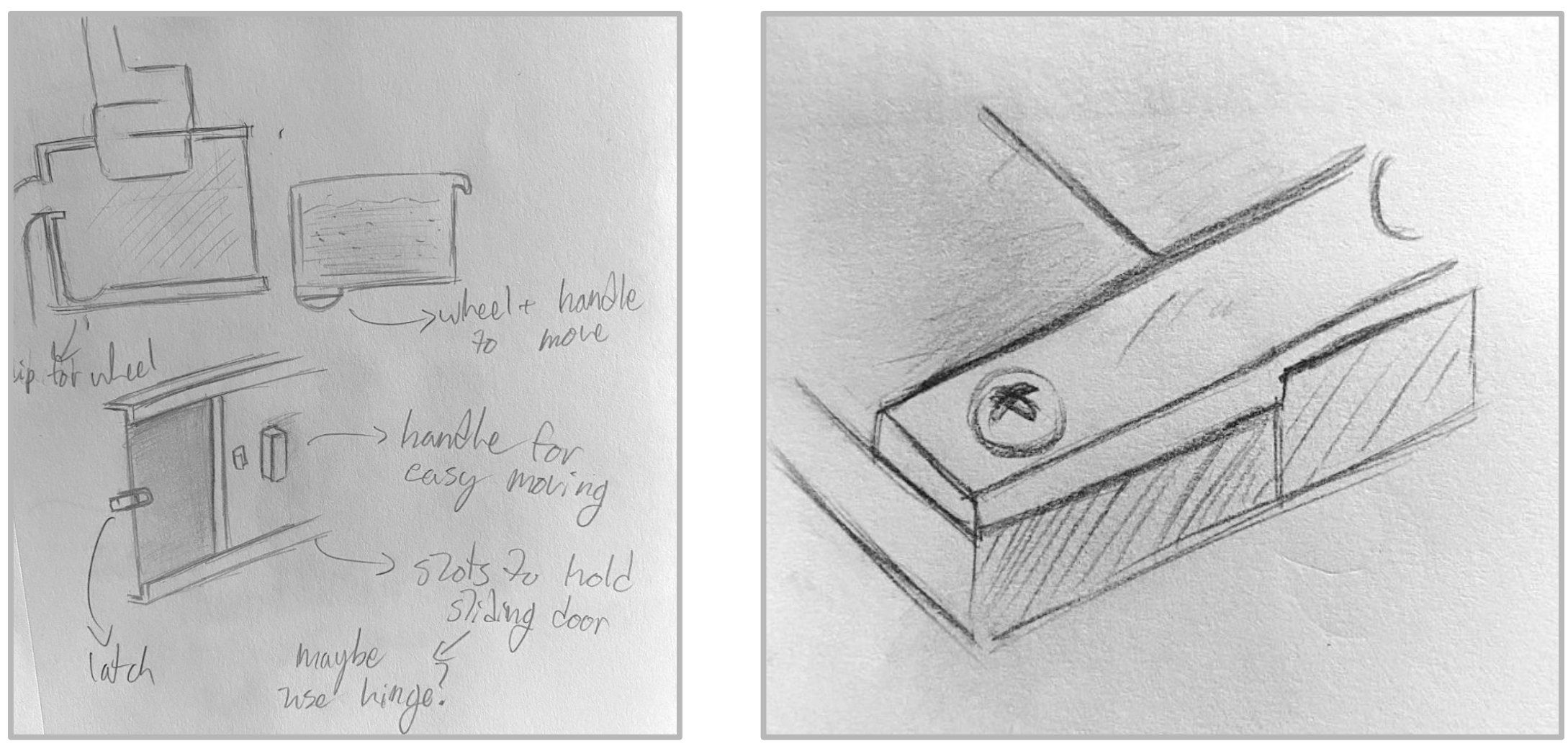

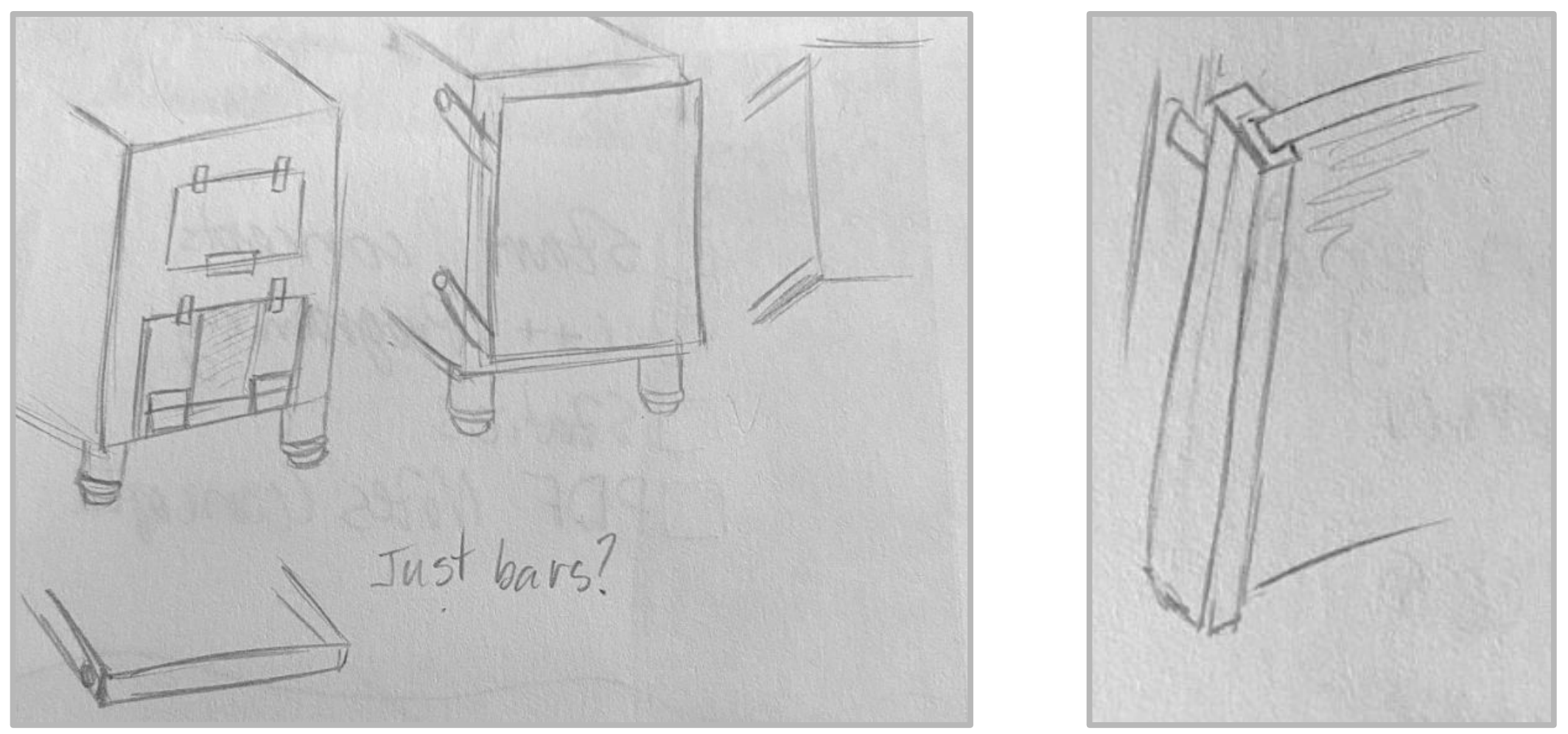

葉 Fermilab 







\section{CAD Models}



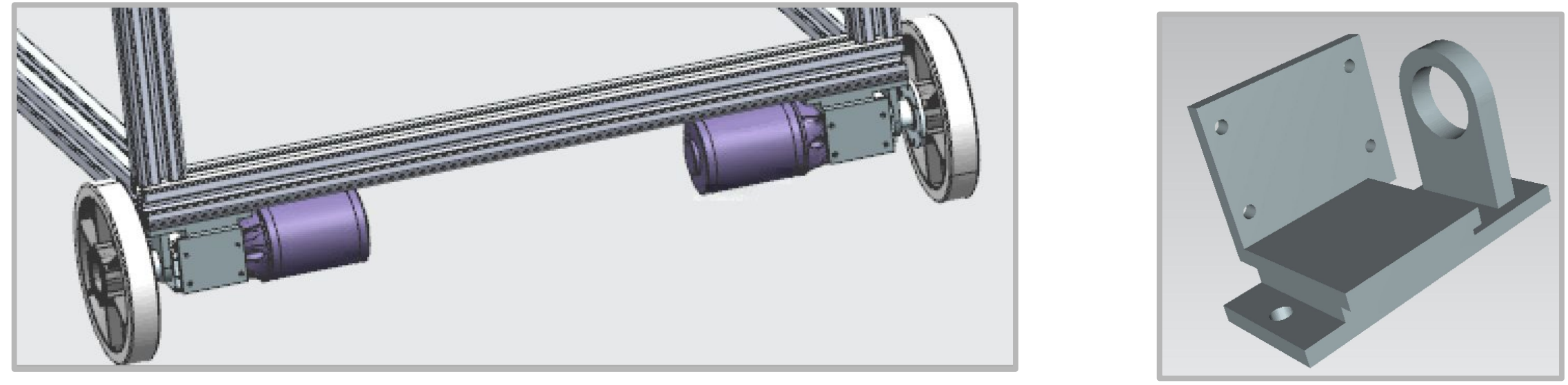

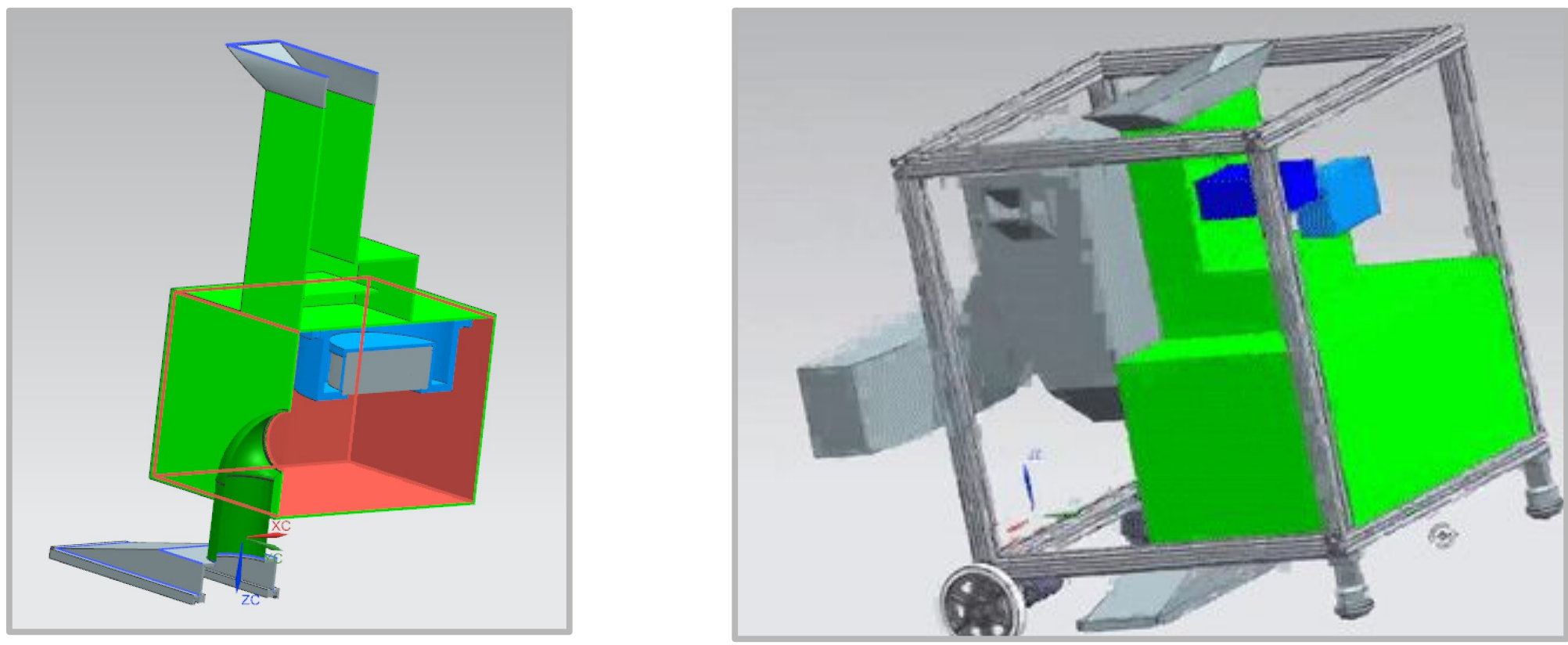

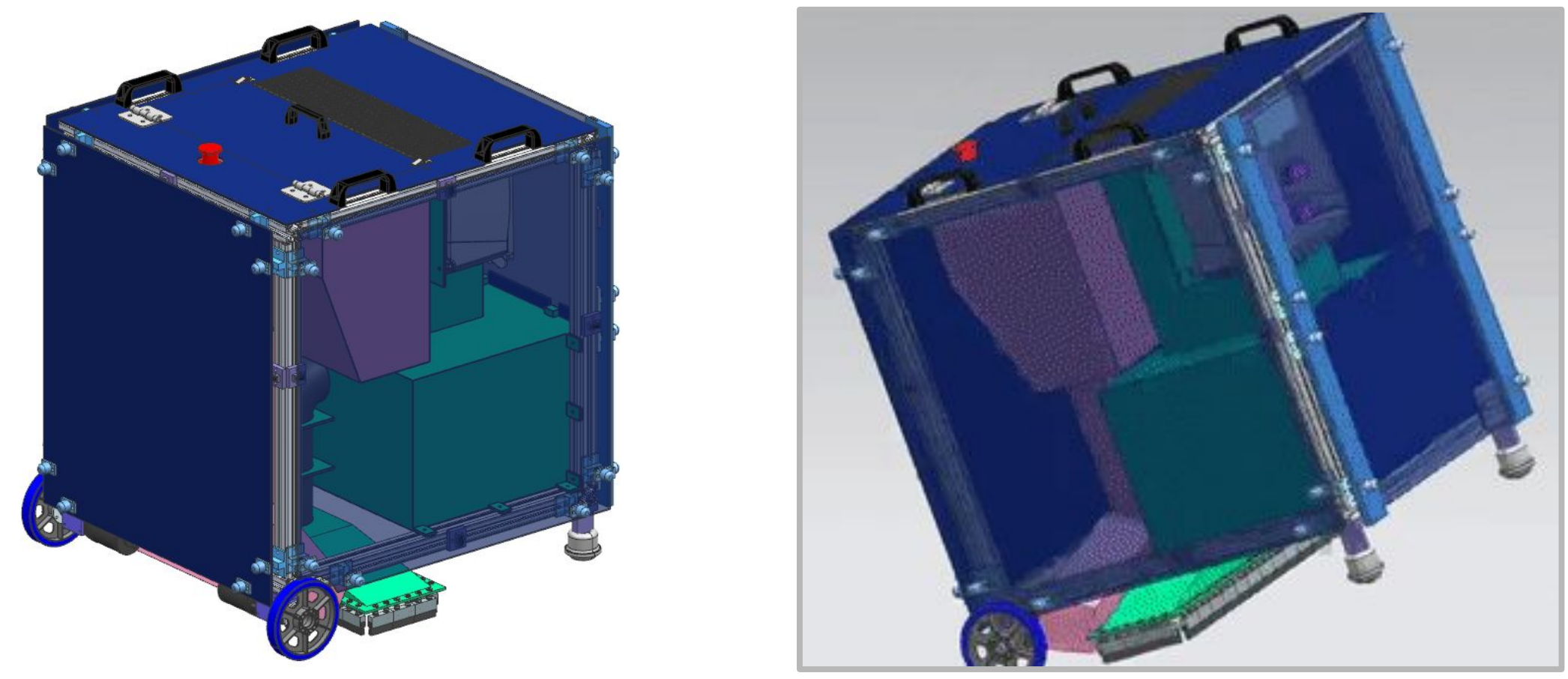


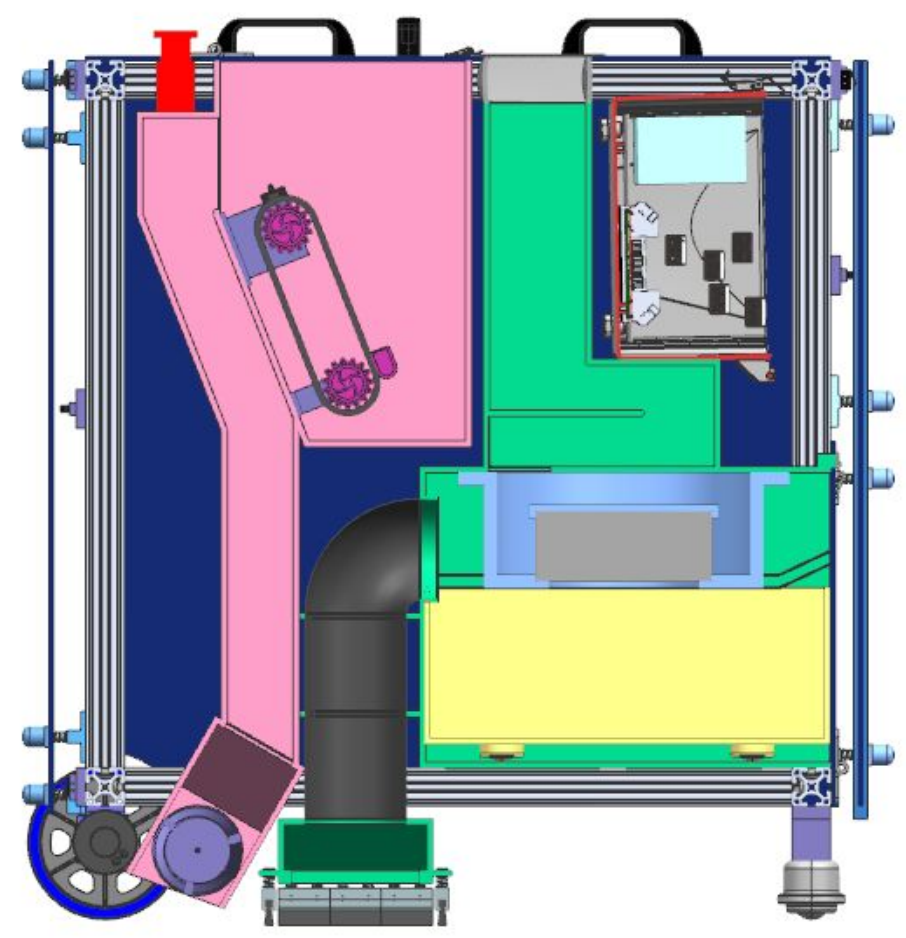



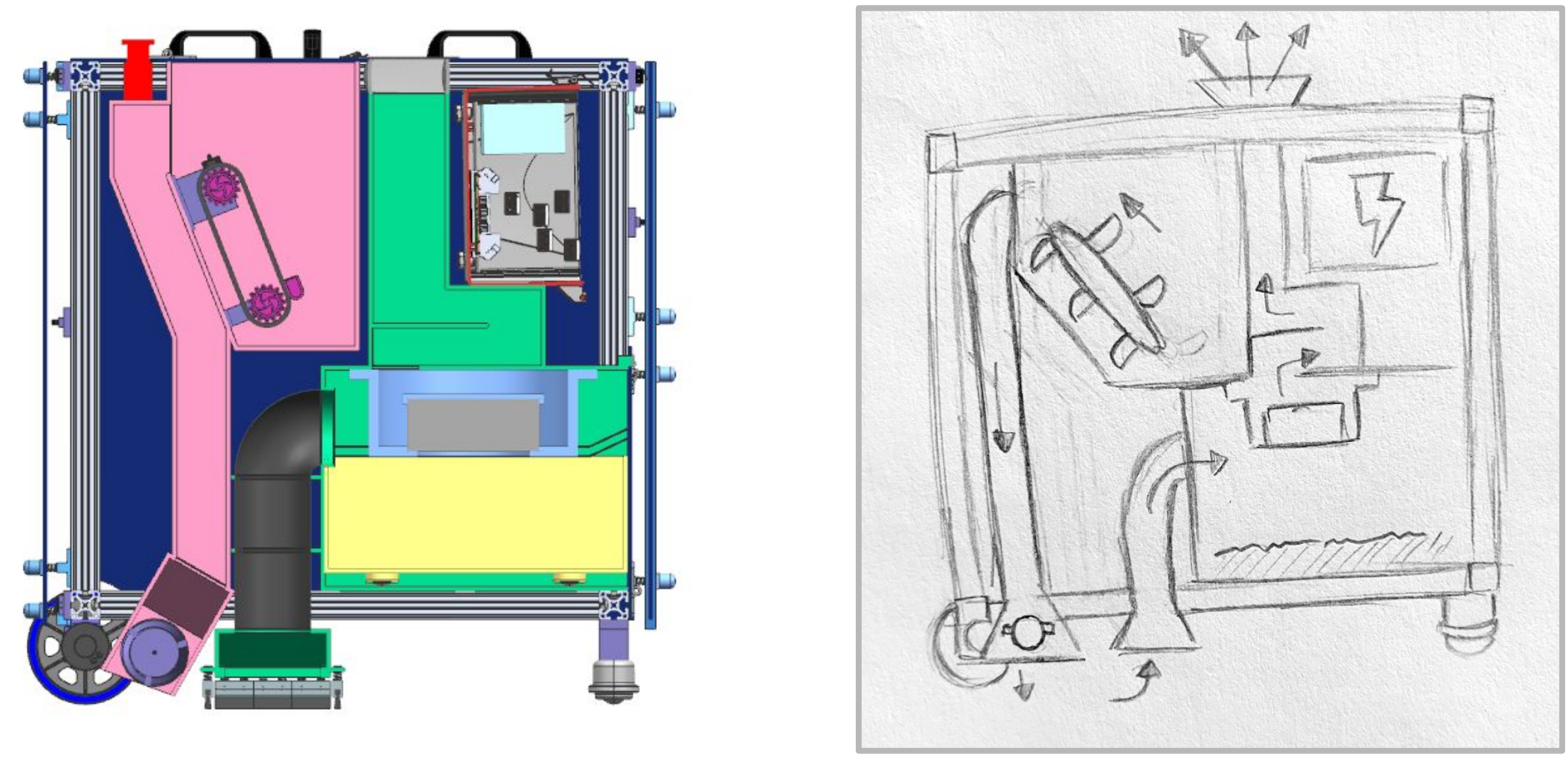

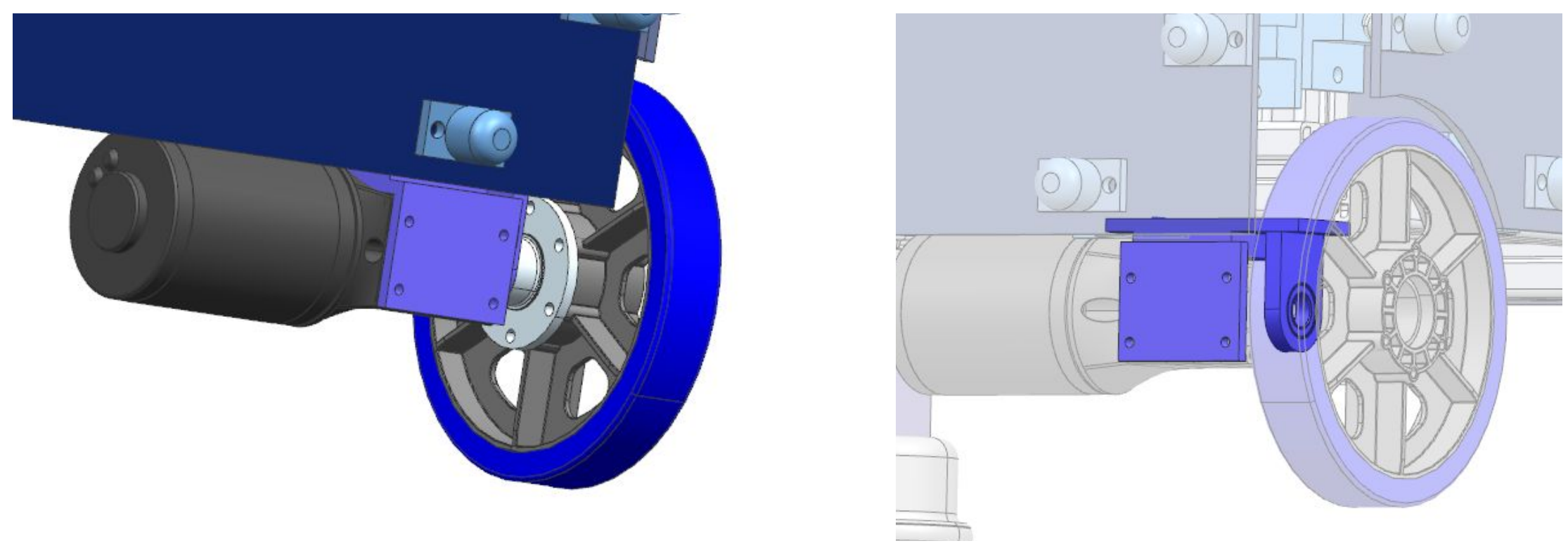

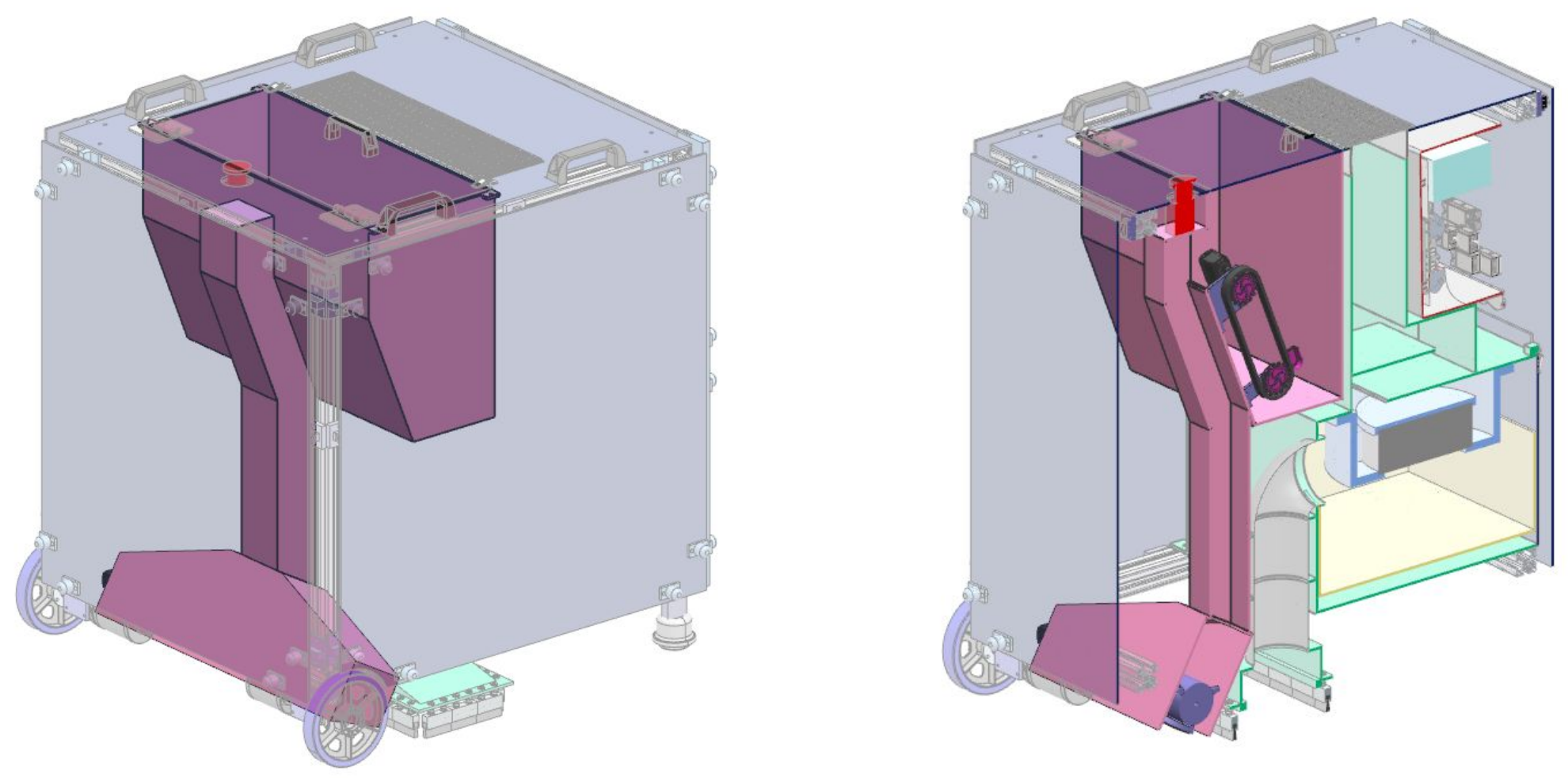

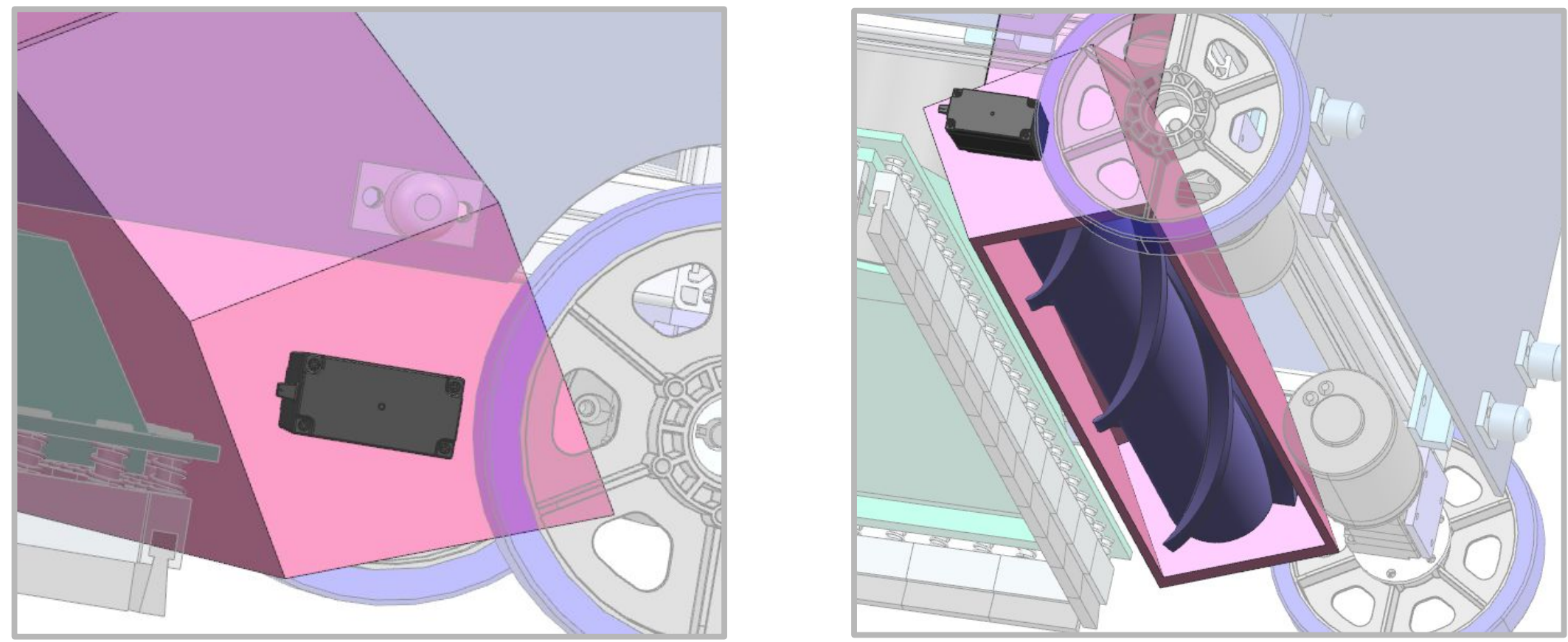

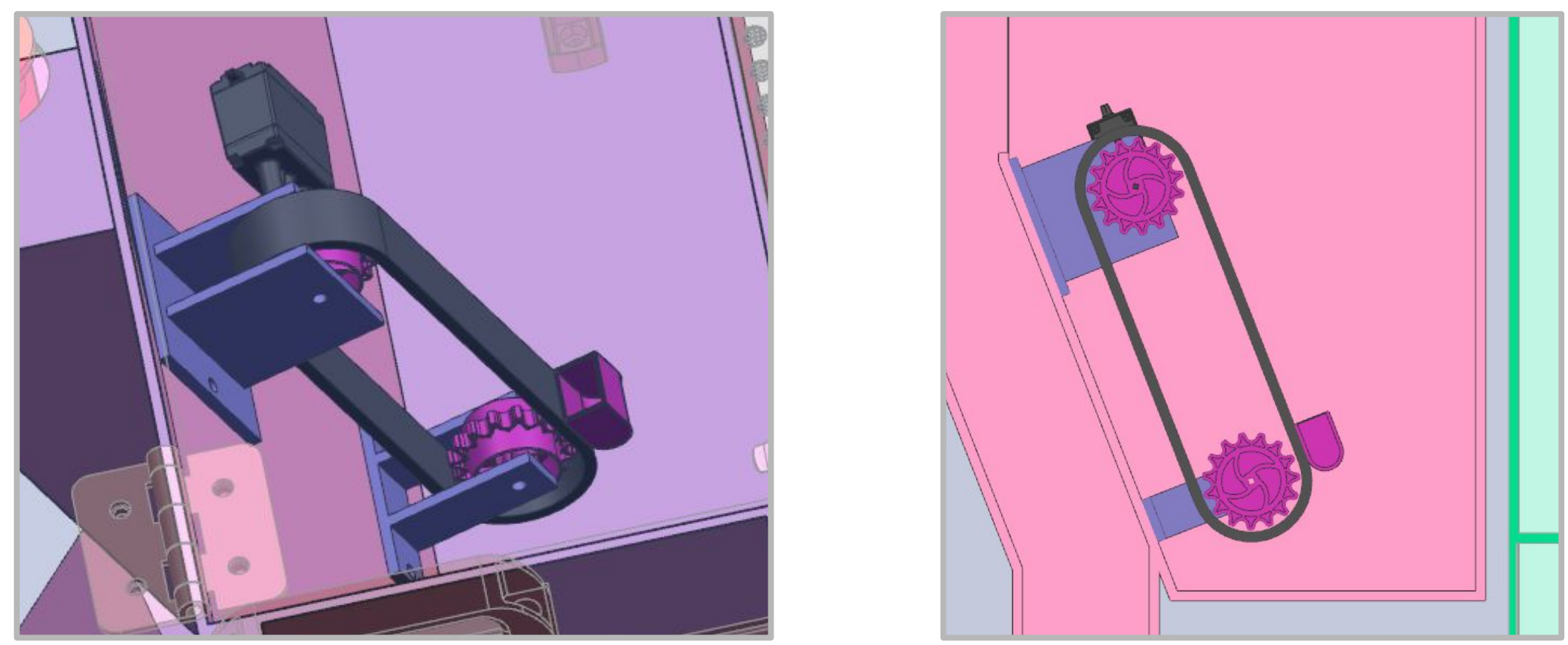

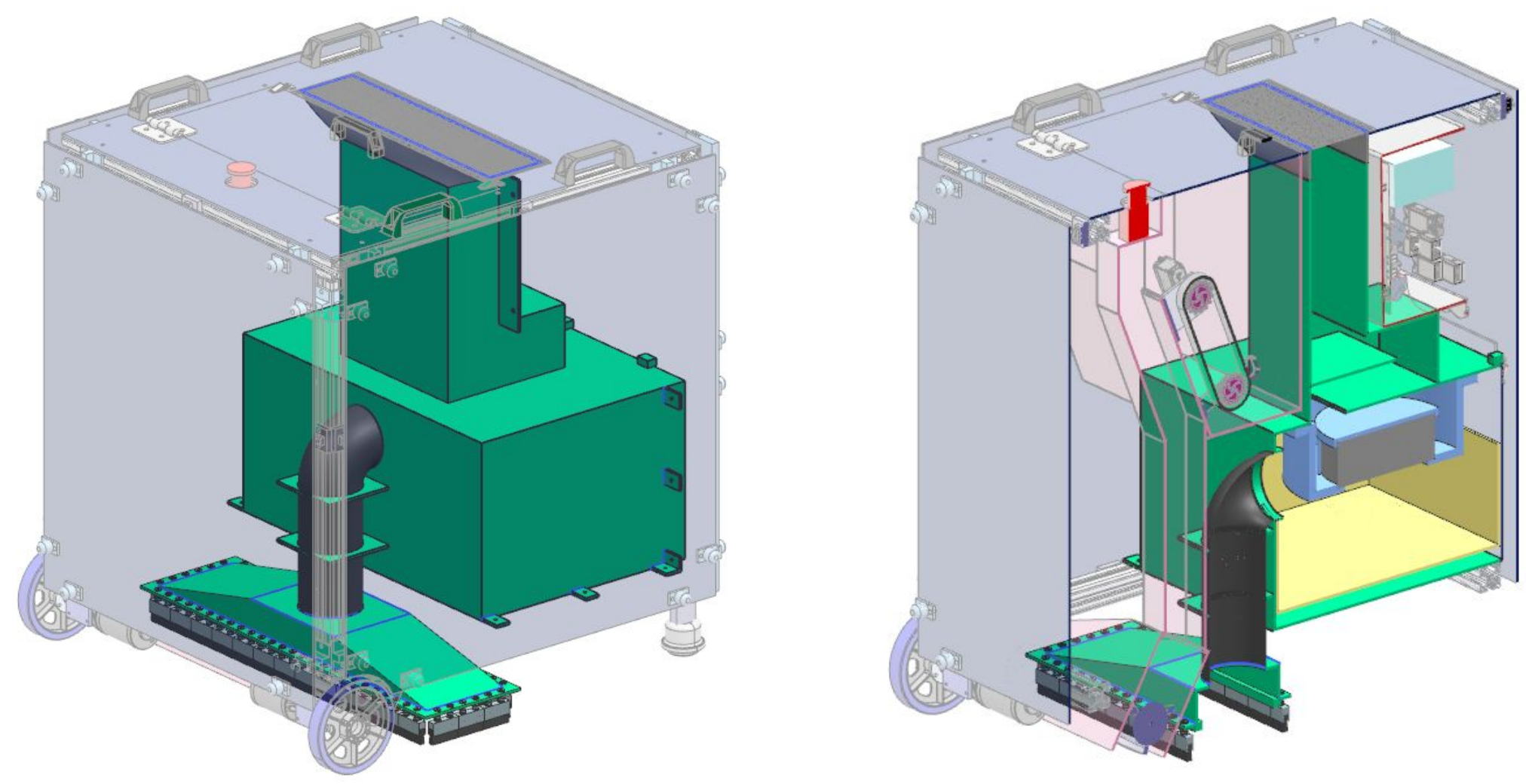

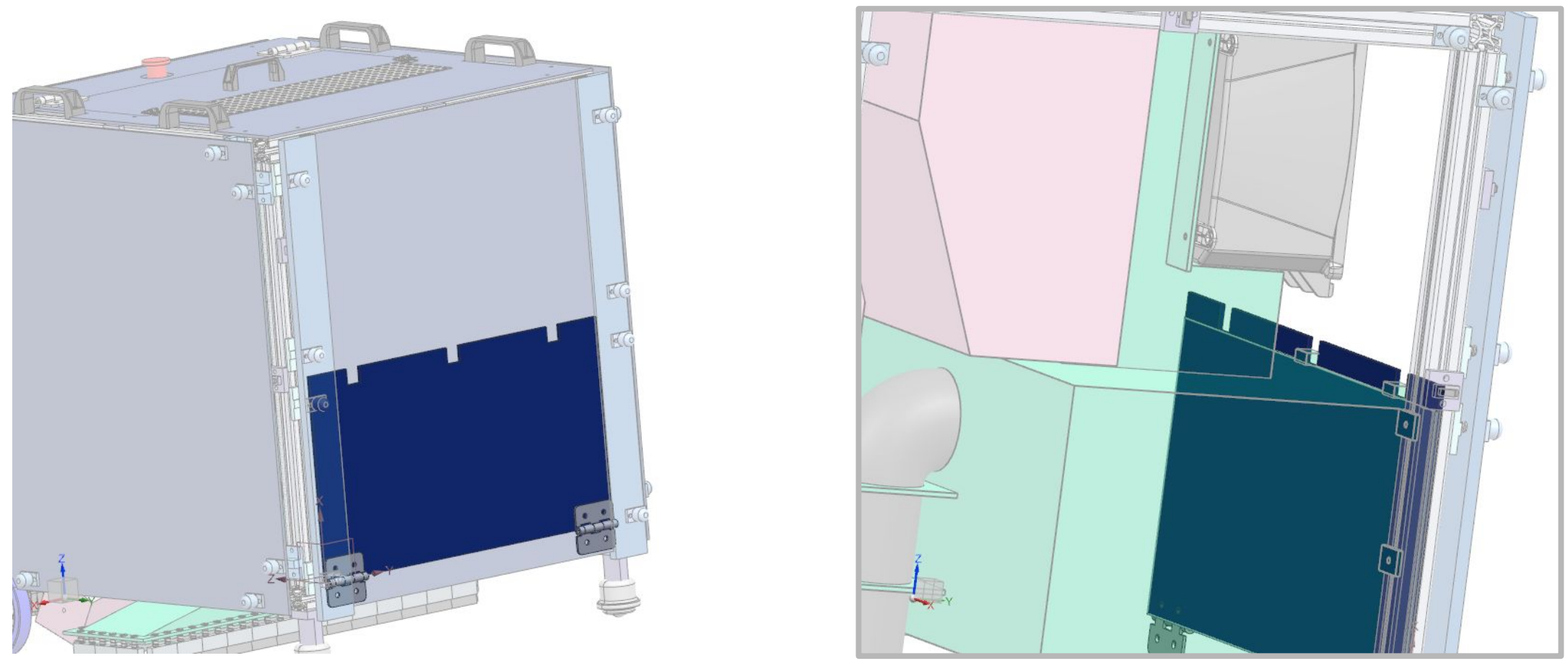


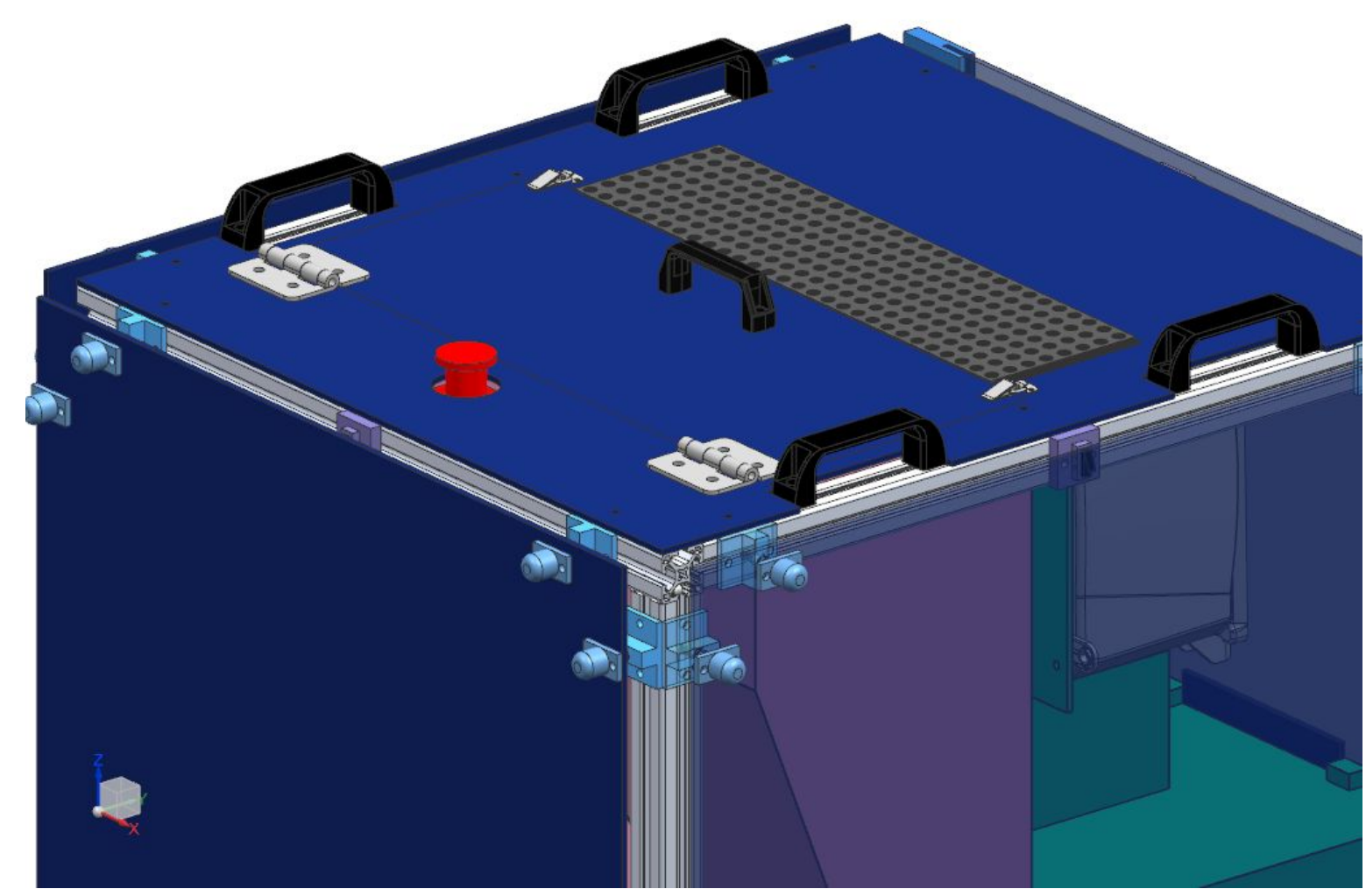




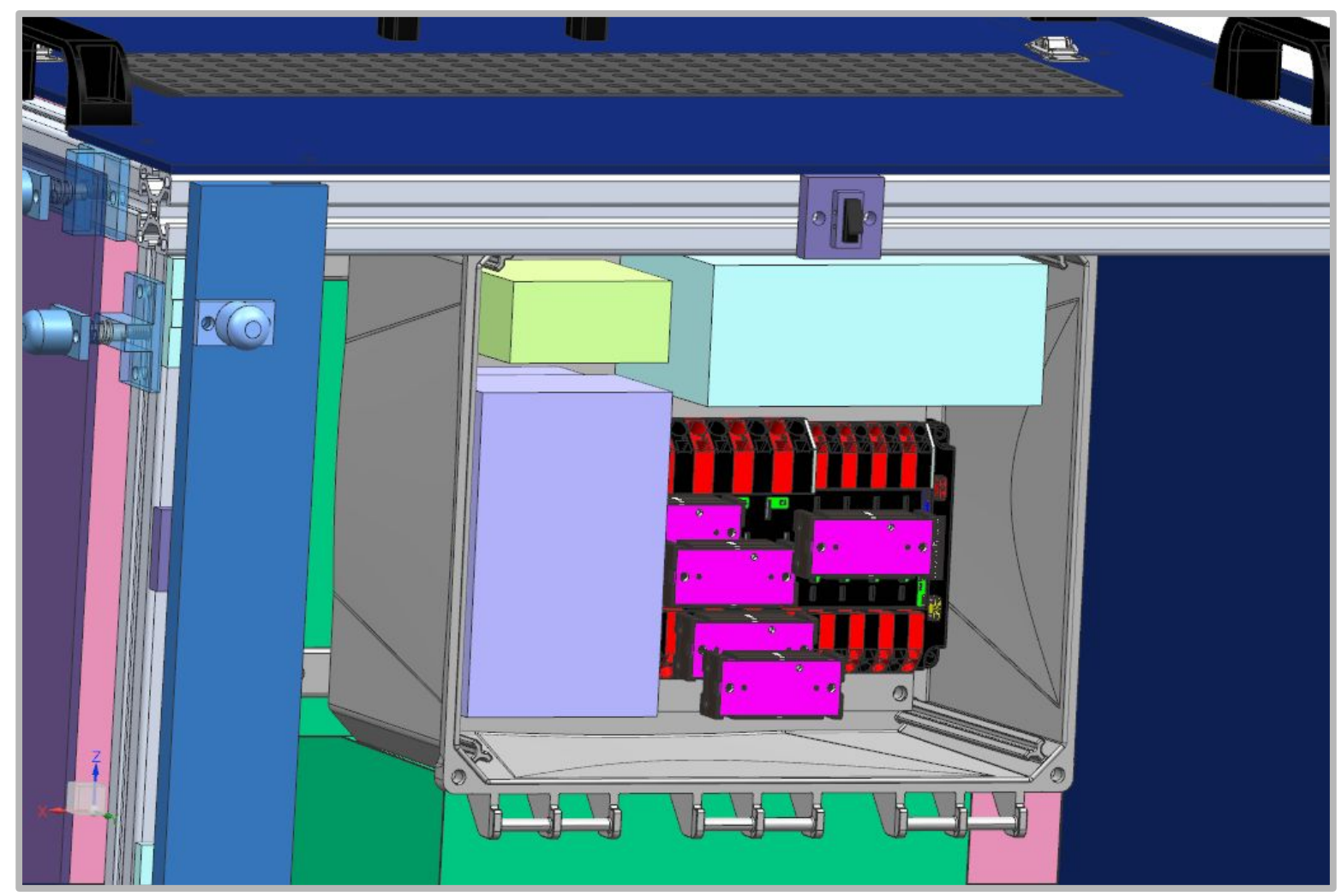



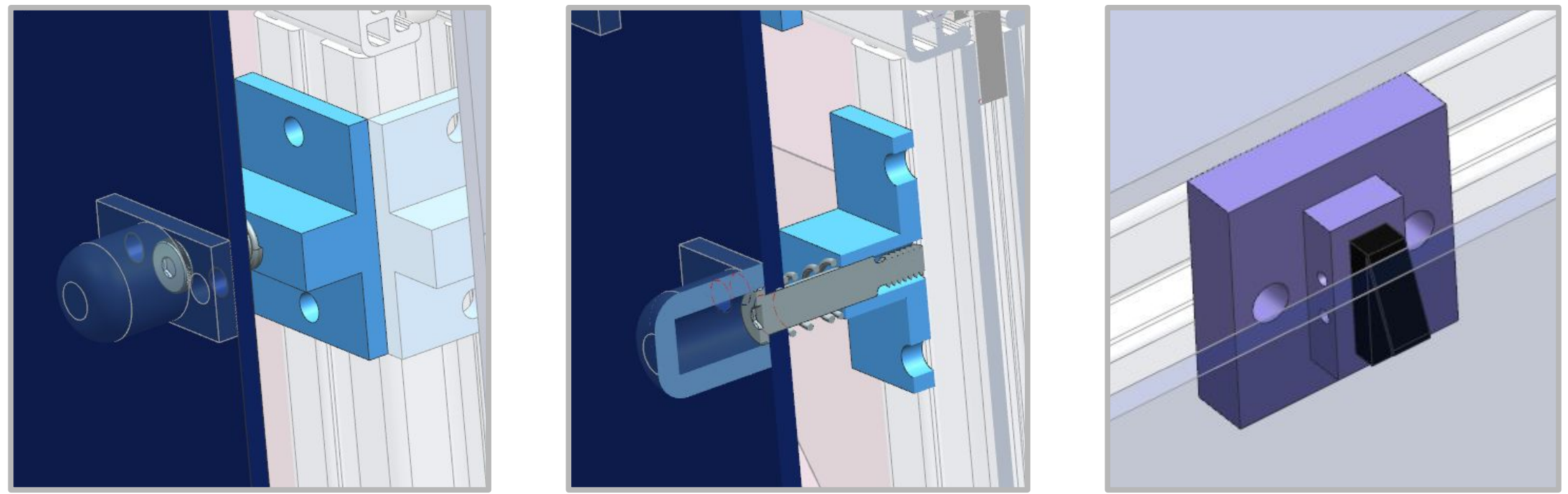

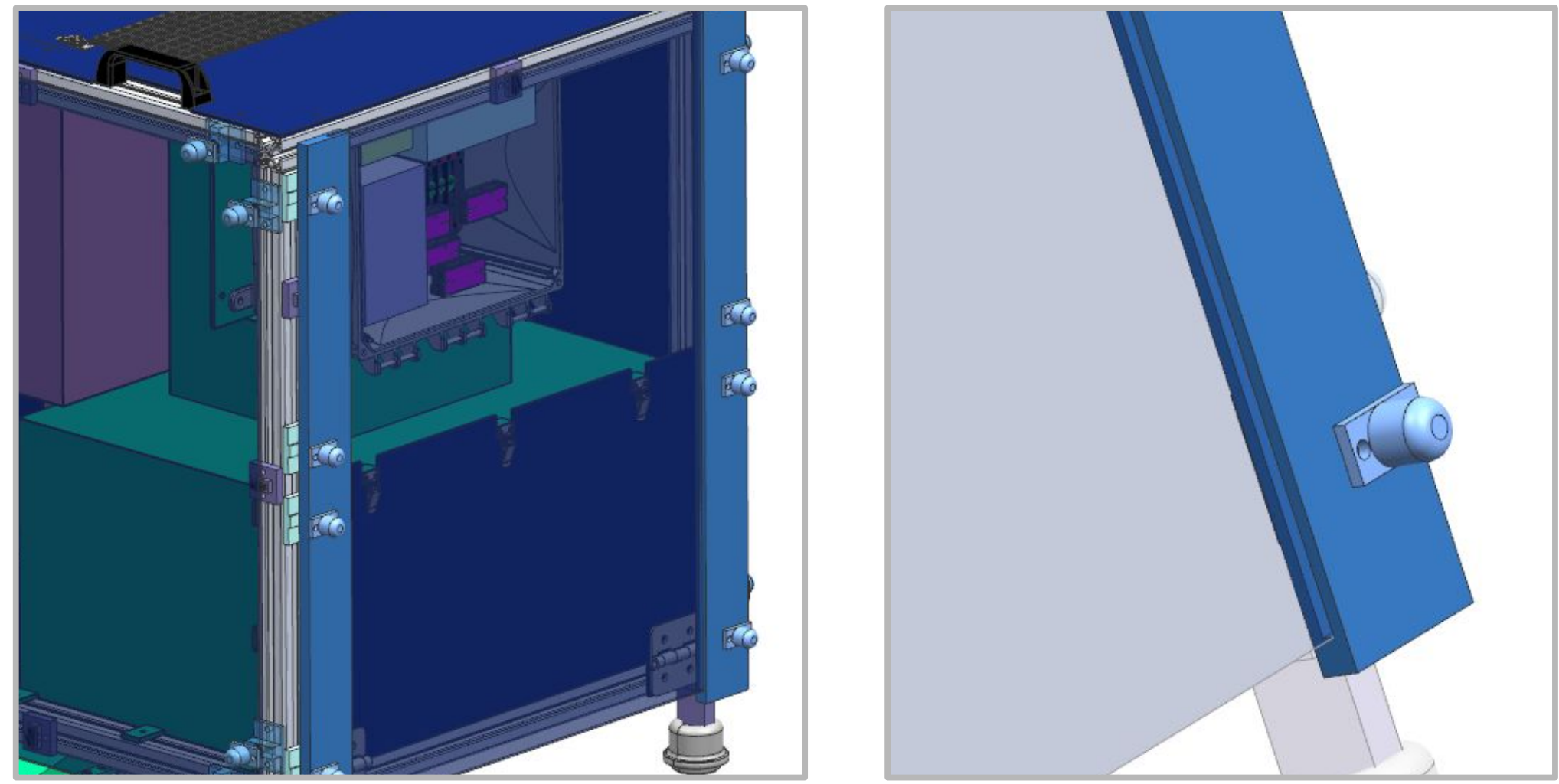


\section{Thank you for attending!}

\section{Any questions?}
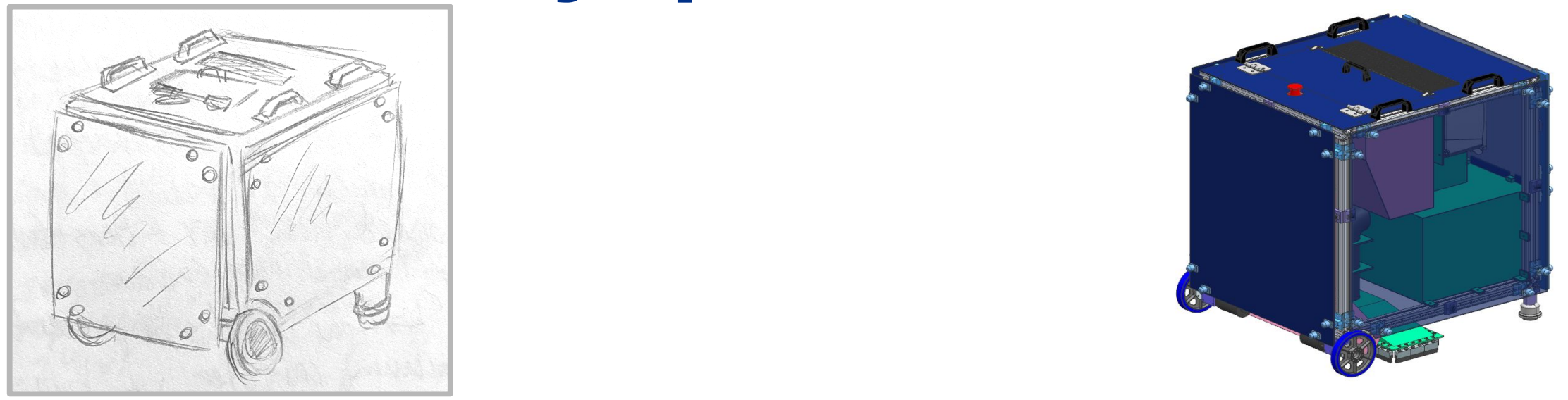